\title{
PALATALIZAÇÃO DO /S/ EM CODA SILÁBICA O PORTUGUÊS FALADO NA COSTA DA LAGOA EM FLORIANÓPOLIS
}

\author{
PATALIZATION OF THE IMPLOSIVE /S/ IN PORTUGUESE SPOKEN IN COSTA DA \\ LAGOA IN FLORIANÓPOLIS
}

\author{
Gabriela Šmaiclová \\ Mestranda em Filologia da Língua Portuguesa \\ Universidade Carolina em Praga, República Tcheca
}

\begin{abstract}
Resumo
O presente artigo aborda o fenômeno de palatalização do /s/ em coda silábica na fala dos moradores nativos do bairro Costa da Lagoa do município de Florianópolis no estado de Santa Catarina (Brasil) sob a perspectiva da Teoria da Variação Linguística laboviana. A região estudada caracteriza-se pela influência da colonização dos portugueses originários das ilhas dos Açores e da Madeira. A conservação das tradições culturais, do estilo de vida e a valorização dos costumes dos antepassados são considerados fatores importantes para o entendimento da comunidade observada. Encontramos nessa resistência respostas extralinguísticas para a presença da palatalização da fricativa alveolar na fala dos informantes. Uma parte dos dados utilizados para esta análise quantitativa faz parte do Banco de Dados do Projeto VARSUL e outra parte foi coletada por nós entre junho e julho de 2009. As hipóteses foram levantadas principalmente com base nos estudos de Brescancini (1996) sobre a palatalização do /s/ em posição de coda silábica em outras regiões do município de Florianópolis. A análise estatística foi submetida ao programa computacional GOLDVARB 2001.
\end{abstract}

Palavras-chave: Português. Ilha de Santa Catarina. Palatalização do /s/ implosivo. Teoria da Variação Linguística.

\begin{abstract}
This paper studies the phenomenon of palatalization of the implosive /s/ in the speech of habitants natural from the district Costa da Lagoa in the county of Florianópolis in the Santa Catarina state in Brazil under the perspective of the Labov's Linguistic Variation. The studied region's characteristic is an essential influence of the colonization of Portuguese people natural from Açores and Madeira islands. We consider the conservation of cultural traditions, the life style and valorization of costumes of the ancestors important factors for the comprehension of the observed community and in this resistance we find some extralinguistic answers for the presence of the palatalization of the alveolar fricative in our informers' speech. One part of the data utilized for the quantitative analysis is a part of the Databank of the Project VARSUL (Linguistic Urban Variation of the South Region) and the other part was collected by us in June and July in 2009. The hypotheses were based principally on studies about the palatalization of the $/ \mathrm{s} /$ in the implosive position in other regions of the county Florianópolis from Cláudia Regina Brescancini. The statistic analysis was submitted to the computer program GOLDVARB 2001.
\end{abstract}


Keywords: Portuguese. Santa Catarina Island. Palatalization of the implosive /s/. Linguistic Variation Theory.

\section{CARACTERIZAÇÃO DO FENÔMENO EM ESTUDO}

Uma consoante é produzida com a aproximação dos órgãos articulatórios, pelo que se cria um estreitamento/obstrução que impede a passagem livre do ar. Cada alteração da posição dos órgãos articulatórios leva a mudanças audíveis.

As sibilantes ou fricativas alveolares pertencem ao subgrupo das consoantes em cuja produção percebe-se um ruído de fricção gerado pelo estreitamento do trato oral. Esse ruído é igualmente percebido na produção das chiantes ou fricativas palatoalveolares. Esses dois subgrupos diferem em relação (a) à zona de articulação - para as sibilantes acontece nos alvéolos e para as chiantes ocorre na parte anterior do palato duro; (b) ao tamanho da abertura do estreitamento, sendo menor para as sibilantes; (c) à posição dos lábios que passa a ser arredondada na produção das chiantes; (d) à posição do dorso da língua que se abaixa para as sibilantes e eleva-se para as chiantes.

A variabilidade na produção das sibilantes e das chiantes, pode ser explicada pela sua complexidade fonética "por exigirem um gesto articulatório adicional" (BRESCANCINI, 1996, p. 7). Encontramos provas da frequente assimilação, enfraquecimento, aspiração ou queda das consoantes estudadas em todas as posições em várias línguas. Na própria gramática histórica do português, acontece a crase das sibilantes especialmente na posição final. $\mathrm{O}$ sistema consonântico da língua portuguesa distanciou-se do galego por volta de 1350 e, a partir desse momento, passou por várias mudanças ortográficas e fonéticas. Em certas épocas, havia mais do que um sistema de sibilantes em Portugal. Segundo Teyssier (1984), o primeiro registro de pronúncia palatal do /s/ em final de sílaba foi em 1746 por Luís António Verney. Existem mais hipóteses sobre as causas da existência do fenômeno e sobre a época dessa transformação, mas os pesquisadores concordam que, na época da imigração açoriana para Santa Catarina, no século XVIII, "o centro-sul de Portugal já produzia a palatalização do /s/ e /z/ em final de sílaba e de palavra" (BRESCANCINI, 1996, p. 38).

Brescancini (1996) resume duas hipóteses dos investigadores estudados para a justificativa da adoção do fenômeno em questão no litoral de Santa Catarina: a primeira é de que os açorianos não exerceram influência considerável sobre a pronúncia brasileira, pois se misturaram com transmontanos, minhotos, alentejanos, algárvios. Afirma que algumas áreas de povoamento açoriano no Brasil não produzem a variante palatal. E quanto ao estado de Santa Catarina, o fenômeno ultrapassa o ponto terminal da distribuição inicial de sesmarias a açorianos. Assim, o prolongamento do falar das ilhas, citado acima, só poderia ter como destino ou sua absorção pela língua comum, propagada pelas escolas, ou sua absorção por outros falares brasileiros. A segunda hipótese propõe que a palatalização teve sua origem no intercâmbio entre os açorianos instalados na Ilha de Santa Catarina, e a capital federal da época - Rio de Janeiro - bem como no intercâmbio com outras cidades como Santos, Salvador, Recife, além do intercâmbio direto com Lisboa, sendo a capital do Estado de Santa Catarina o pólo que concentrou 
não só os povoadores lusoaçorianos, mas também a posterior comunicação com os centros irradiadores da pronúncia palatal, a saber, Lisboa e, depois Rio de Janeiro (...) a influência maior deve ter-se originado do Rio de Janeiro, através do contínuo vai-e-vem da elite administrativa, social e intelectual entre a capital federal e essas cidades portuárias. (BRESCANCINI, 1996, p. 41-46).

Uma observação é certa: "a variante palatal em final de sílaba produzida na região litorânea central de Santa Catarina diferencia-se da variante produzida em mesma posição nos estados vizinhos do Rio Grande do Sul e Paraná e no interior do próprio estado, mas assemelha-se a outros falares brasileiros de forte influência portuguesa, como o carioca e o nordestino" (BRESCANCINI, 1996, p. 49). Adotamos a conclusão de Brescancini: “(...) o denominador comum para tal fenômeno no Brasil parece ser antes o falar do centro-sul de Portugal, que chegou até aqui via imigração açorianomadeirense" (BRESCANCINI, 1996, p. 49).

\section{BASES DA TEORIA DA VARIAÇÃO}

Com o surgimento da noção de paradoxo saussereano, segundo o qual o aspecto social da língua é estudado pela observação de qualquer indivíduo, mas o aspecto individual somente pela observação da língua em seu contexto social, Labov (2008 [1972], p. 218) manifesta as suas convicções: as pressões sociais estão operando continuamente sobre a língua, não de algum ponto remoto no passado, mas como uma força social imanente agindo no presente vivo (LABOV, 2008 [1972], p. 21). Weinreich, Labov e Herzog (2006 [1968]) também criticaram as teorias de Chomsky dando importância à variação linguística de um ponto de vista prático ou aplicado. Surge o modelo de análise linguística denominado Teoria da Variação, iniciado por William Labov (2008 [1966]). Desenvolveu-se a partir daí o conceito de regra variável, cujo objetivo é descrever a variação interna e socialmente determinada dos dados linguísticos encaixados da forma como ocorrem em situações de fala concreta. Essa Teoria assume a língua como um sistema heterogêneo e assim elimina a busca por falantes ideais. As regras variáveis desenvolvidas por Labov dão valor não só à presença ou ausência de elementos linguísticos, mas também aos fatores extralinguísticos como a idade, sexo, escolaridade, classe socioeconômica, etc.

A Teoria da Variação fornece um instrumental metodológico que permite medir o efeito com que uma categoria contribui para a realização ou não de uma variante. Considerando aspectos linguísticos e extralinguísticos, realiza estatísticas e mede probabilidades para entender a aplicação de uma regra. $\mathrm{O}$ favorecimento de uma das variantes no decorrer do tempo e o consequente desaparecimento da forma desfavorecida sinalizam que a regra variável em estudo caracteriza um processo de mudança linguística. A análise da frequência e peso relativo possibilita a apreciação do desenvolvimento de uma dada forma linguística na comunidade onde ocorre, valorizando tanto o papel do condicionamento social, quanto o papel do condicionamento linguístico no processo de variação e mudança linguística.

O primeiro trabalho de William Labov (2008 [1966]) que dá importâcia aos fatores sociais na mudança linguística foi realizado na Ilha de Martha's Vineyard, no estado de Massachussets nos Estados Unidos em 1963. A pesquisa investiga a variação dos 
ditongos [ay] e [aw] no falar dos habitantes da dita ilha. Esse estudo foi considerado importante por vários linguistas, entre os brasileiros especialmente os de Santa Catarina, uma vez que a Ilha estudada por Labov apresenta algumas semelhanças com a Ilha de Santa Catarina: a estrutura social, o aspecto econômico dos habitantes, salário baixo, desemprego, falta de indústrias, grande mercado pesqueiro, invasão de proprietários não nativos, dependência econômica crescente por parte da população nativa nos meses de veraneio. Segundo as conclusões de Labov, os nativos apresentam resistência a qual se reflete na fala. Para se distinguir dos veranistas e manter a própria identidade, os moradores produzem o fenômeno de centralização da vogal do ditongo (LABOV, 2008 [1963]). As técnicas pioneiras utilizadas no estudo mencionado acima foram desenvolvidas na dissertação de Labov investigando a estratificação social do inglês falado na cidade de New York, publicada em 1966 e tomada como a obra inaugural da Teoria da Variação (LABOV, 2008 [1966]).

\section{DESCRIÇÃO DA COMUNIDADE DE FALA}

A Costa da Lagoa é uma típica colônia de pescadores que ainda preserva algumas construções que lembram o desenvolvimento do local, como alguns engenhos, casarões e sobrados.

Os dados referentes à população atual da região estudada apresentados nas Tabelas foram retirados do site da Secretaria Municipal de Saúde, da Prefeitura Municipal de Florianópolis. ${ }^{1}$

TABELA 1. População de Florianópolis

\begin{tabular}{c|c|c}
\hline Residentes & Homens residentes & Mulheres residentes \\
\hline 402346 & 194825 & 207521 \\
\hline
\end{tabular}

TABELA 2. População de Costa da Lagoa

\begin{tabular}{c|c|c|c|c|c|c|c|c}
\hline Anos & $\mathbf{0}$ & $\mathbf{1}$ a 5 & $\mathbf{5}$ a 9 & $\mathbf{1 0}$ a 19 & $\mathbf{2 0}$ a 49 & $\mathbf{5 0}$ a 59 & $\mathbf{6 0}$ ou mais & Total \\
\hline Residentes & 12 & 54 & 66 & 135 & 420 & 46 & 57 & 778 \\
\hline Homens & 6 & 27 & 36 & 71 & 223 & 21 & 21 & 399 \\
\hline Mulheres & 6 & 27 & 30 & 64 & 197 & 25 & 36 & 379 \\
\hline
\end{tabular}

Embora tenhamos encontrado números muito díspares em relação à populacão da comunidade da Costa da Lagoa, adotamos os acima mencionados como verdadeiros para a nossa pesquisa.

Quanto ao perfil dos moradores, divide-se a população da Costa da Lagoa em dois grupos: os antigos e os novos moradores, ou, os nativos e os "de fora" que, além da procedência, têm diferentes discursos e ações relativas aos ecossistemas locais. Os moradores novos da Costa da Lagoa geralmente não participam das atividades da comunidade, desde a pesca até as festas religiosas. Os moradores nativos da Costa da Lagoa podem também ser divididos em dois grupos: os que trabalham na Costa nos restaurantes ou para os restaurantes, e raramente saem da Costa; e os que trabalham fora da Costa da Lagoa e em cada dia útil precisam sair da localidade. Como entendido na

\footnotetext{
${ }^{1}$ Censo Demográfico IBGE 2000 (Estimativa 2008) atualizado em dezembro de 2008
} 
pesquisa realizada, mesmo as pessoas que enfrentam a trajetória cotidiana de 40 minutos de barco, e às vezes ainda mais de ônibus para o Centro da cidade ou aos outros bairros na Ilha, não trocariam a Costa por nenhum outro lugar para morar.

O barco faz a ligação principal da Costa da Lagoa com o Centrinho da Lagoa. A Cooperbarco oferece horários regulares e pode-se descer nos dezenove pontos de parada ao longo da costa. Não existe estrada para a Costa da Lagoa, portanto o barco é o único meio de transporte seja coletivo, seja individual. Das entrevistas usadas para a pesquisa percebemos que os moradores da Costa, que trabalham na Costa, utilizam o barco para fazer compras de duas até três vezes por mês. Além disso, os mesmos saem dali geralmente só para ter uma consulta específica no médico, para utilizar serviços das instituições que não existem no bairro como as de correio, de banco, etc. Na Costa da Lagoa há uma escola primária e creche, um posto de saúde e duas igrejas. A eletricidade chegou ao bairro em 1984. Na comunidade falta uma ligação de esgoto coletivo a uma estação de tratamento. O projeto do esgoto coletivo na Costa da Lagoa existe há muitos anos e até hoje não foi realizado.

A Costa tem mais de quinze restaurantes que funcionam o ano inteiro. O cardápio é frutos do mar: uma comida simples feita pelos próprios moradores tem como matériaprima o resultado do trabalho dos pescadores locais. Maior parte do trabalho dos habitantes nativos que pouco saem da Costa está voltado aos restaurantes. Durante o ano inteiro, mas principalmente na época do verão, a Costa da Lagoa recebe uma quantidade imensa de turistas que vêem admirar as belezas e a tranquilidade desta região, tornando assim esse tipo de trabalho principal meio de sobrevivência. $\mathrm{Na}$ comunidade existem poucas rendeiras ativas, geralmente bastante idosas. A maioria das mulheres nativas que aprendeu a fazer renda na infância já não costuma procurar neste meio a fonte de renda. No bairro há uma pousada e poucos bares noturnos.

Das entrevistas com os informantes foi percebido que há uma preocupação recente em relação à construção de uma estrada e de um resort de hotéis na área. Os moradores apresentam uma resistência e não concordam com tal impacto na paisagem e na tranquilidade da vida que levam. Todos demostraram grande amor pelo lugar e pelo sossego dele, argumentaram com a inexistência de assalto, roubo e outros perigos. Observando as redes sociais dos moradores afirmou-se o fato de todas serem ligadas seja por relação parentesca, seja por relação de amigos ou conhecidos.

\section{METODOLOGIA}

Para verificar o comportamento da fricativa coronal foram utilizadas 8 entrevistas, 5 amostras coletadas por nós e 3 provenientes do banco de dados do Projeto VARSUL. Todas as entrevistas duram entre 20 e 60 minutos. O tempo das entrevistas utilizado na pesquisa foi 10 minutos de cada uma.

A seleção de informantes segue a metodologia do trabalho do Projeto VARSUL. Os informantes selecionados cumprem os seguintes requisitos: ser falante do português brasileiro; ser nascido e ter crescido na região de Costa da Lagoa; ser filho de pais também originários da região e descendentes de açorianos; ter vivido $2 / 3$ de sua vida na região; incluir-se nas faixas etárias selecionadas e ter um dos níveis de escolaridade 
selecionados. Os informantes foram divididos em células segundo as mesmas características sociais como se vê na Tabela 3.

TABELA 3. Distribuição dos informantes por célula social

\begin{tabular}{c|c|c|c}
\hline EscolaridadelFaixa Etária & $\mathbf{1 5 - 2 5}$ anos & $\mathbf{2 6 - 5 0}$ anos & $\mathbf{+ 5 0}$ anos \\
\hline Primário & 1 & 2 & 2 \\
\hline Superior & 1 & 2 & $/$ \\
\hline
\end{tabular}

Não foi possível controlar a variável 'escolaridade' nos seus dois níveis de escolaridade por não encontrarmos indivíduos de mais de 50 anos de idade que tenham grau de ensino superior a básico.

No trabalho de campo, procuramos realizar a pesquisa sociolinguística (modelo adotado pelo Projeto VARSUL) e técnicas de pesquisa de campo etnográfica para podermos enriquecer o nosso conhecimento sobre a comunidade e também nos aproximarmos dos informantes entrevistados, de modo que a fala deles fosse o mais espontânea possível, e assim valiosa para o nosso estudo. Realizamos estudos históricos, etnográficos e culturais antes da nossa ida a campo, preparando assim um roteiro mais adequado para atingir o nosso objetivo. Procuramos evitar questões que induzissem o informante a responder apenas "sim" ou "não". Direcionamos as questões para a vida cotidiana dos informantes, para histórias de família, de infância e do bairro com o intuito de obter uma fala empenhada e espontânea no momento de gravação. A presença do gravador e a necessidade de uma fala natural retrata justamente o "paradoxo do observador" do qual trata Labov (LABOV, 2008 [1972], p. 223). Procuramos lidar com esse problema e fizemos o possível para que o informante não se sentisse observado.

Das 8 entrevistas, foi utilizado um total de 80 minutos, correspondendo, como já colocamos anteriormente, a 10 minutos de cada informante, totalizando 737 ocorrências de $/ \mathrm{s} /$. Os dados de algumas entrevistas foram retirados de vários momentos para obtermos um vocabulário mais diferenciado. A codificação dos dados foi realizada de acordo com as variáveis selecionadas e submetidas ao programa de análise computacional GOLDVARB 2001.

\section{AS VARIÁVEIS CONTROLADAS E AS HIPÓTESES INICIAIS}

Para levantar as hipóteses iniciais e compararmos os dados, tomamos por base o estudo de Brescancini (1996) que realiza uma análise quantitativa e fonológica do fenômeno de palatalização do /s/ não-morfêmico em posição de coda silábica na fala de informantes de três regiões do município de Florianópolis/SC. O estudo do fenômeno variável é desenvolvido sob postulados teóricos e metodológicos da Teoria da Variação Linguística laboviana (1966) e o fenômeno fonético-fonológico é analisado sob a perspectiva da Fonologia não-linear - a Geomentria de Traços de Clements. A autora investigou outras regiões da Ilha de Santa Catarina, tais como: o distrito de Florianópolis, Freguesia do Ribeirão da Ilha e Sertão do Ribeirão da Ilha

As variáveis controldas em Brescancini (1996) foram:

A variável dependente - o /s/ em coda - pode ser realizado das seguintes maneiras no português brasileiro: 
1) alveolar surda: go[s]to

2) alveolar sonora: $\mathrm{me}[\mathrm{z}] \mathrm{mo}$

3) palatal surda: go[s]to

4) palatal sonora: me[3]mo

5) fricativa glotal: me[ ]mo

6) zero fonético-apagamento: meømo

Todas as variantes acima apresentadas foram encontradas nos dados de nosso estudo, porém, para a análise, foram consideradas somente as variantes fricativas palatais ([S] e [3]) e fricativas alveolares ([s] e [z]). Foram encontradas ocorrências da realização fricativa glotal e especialmente de apagamento, cuja maioria se concentra nos dados dos informantes menos escolarizados, mas aparecem também nos dados dos informantes escolarizados. No entanto, o número não foi considerado significativo em comparação às realizações palatal e alveolar. Segundo os resultados de Brescancini, a distribuição do fenômeno de apagamento do $/ \mathrm{s} / \mathrm{em}$ coda totalizou $8 \%$ das ocorrências e o fenômeno de aspiração totalizou $1 \%$ dentro dos dados coletados pela autora. Além disso, a maioria dos dados do apagamento da fricativa foge do campo fonológico ao campo morfológico. Por exemplo, na realização [as casaø], o /s/ final da palavra "casas" apaga-se mantendo-se a pluralidade do sintagma no artigo, o que acontece frequentemente no português brasileiro de hoje. Foi considerado que esse fenômeno mencionado merece uma futura investigação.

As variáveis independentes linguísticas controladas durante a análise dos dados foram:

1) A variável sonoridade da consoante seguinte - baseando-nos na hipótese de que os segmentos seguintes, portadores do traço [-voz], ou seja, as consoantes surdas, favorecem a palatalização da coronal anterior surda. A consoante sonora (com o traço [+voz]) não favorece a palatização. $\mathrm{Na}$ análise aqui realizada, foram considerados como fatores condicionantes: surdas, sonoras e zero (os contextos nos quais não havia nenhum segmento seguinte, portanto as pausas).

2) A variável tonicidade - os resultados do estudo de Brescancini (1996) apontam para a maior incidência do fenômeno de palatalização da coronal anterior em contextos tônicos e pré-tônicos, tanto quando se considera o acento de palavra, como quando se considera o acento do grupo de intensidade. Isso confirma a hipótese de que os contextos mais fortes favorecem o fenômeno em estudo.

$\mathrm{Na}$ presente análise, não foi recorrido à divisão do acento da palavra e do grupo de intensidade, observando em geral a sílaba prétônica, tônica e póstônica, consideramos apenas o acento de palavra.

3) A variável tipo de item lexical - os resultados de Brescancini (1996) apontam para os numerais como as mais favorecedoras do fenômeno em questão. No presente estudo, foram selecionados oito fatores nesse grupo, a saber, numerais, substantivos, verbos, adjetivos, pronomes, advérbios $e$ outros, nomes próprios e conjunções. 
4) A variável contexto precedente - segundo os resultados de Brescancini (1996), a vogal dorsal surge como a maior favorecedora do fenômeno estudado, seguida pelas vogais labiais e vogais coronais. Assim, dividimos as vogais nos seguintes fatores: a vogal dorsal [a]; as vogais coronais [i, e, $\varepsilon]$; as vogais labiais [u, o, O]; a semivogal coronal [y]; a semivogal labial [w].

5) A variável contexto seguinte foi julgada a menos significativa estatisticamente no trabalho de Brescancini (1996). Quando selecionada na análise aponta para as consoantes dorsais como maiores favorecedoras do fenômeno em questão.

Neste estudo, igualmente como no estudo da autora, as consoantes foram divididas segundo o ponto de articulação em consoantes dorsais [k, $\mathrm{g}, \mathrm{x}]$; consoantes coronais $[\mathrm{t}, \mathrm{d}, \mathrm{n}, \mathrm{l}, \mathrm{r}]$; consoantes labiais $[\mathrm{p}, \mathrm{b}, \mathrm{m}, \mathrm{f}, \mathrm{v}]$. Além das consoantes controladas também foram consideradas as vogais devido ao fato de que o fenômeno em questão foi encontrado também seguido desse contexto, resumindo todas as vogais em um único fator.

As variáveis sociais escolhidas foram:

1) A variável escolaridade - o maior peso relativo e a maior frequência de ocorrência do fenômeno de palatalização da coronal anterior apresentou-se, no trabalho de Brescancini (1996), entre os indivíduos com nível primário completo ou incompleto. No presente trabalho, foram controlados dois níveis de escolaridade: o nível primário completo ou incompleto (até 4 anos de escolaridade) e o nível superior (graduação completa). Como não foram encontrados moradores nativos da faixa etária de mais de 50 anos na Costa da Lagoa com nível superior, não foi possível considerar esta variável na dita célula.

2) A variável idade - os resultados de Brescancini (1996) confirmam a ocorrência de maior índice de palatalização da consoante em questão na faixa mais jovem. Na análise do presente trabalho, foram considerados três níveis de estratificação: 15 até 25 anos; 26 - 50 anos; mais de 50 anos.

\section{DESCRIÇÃO E ANÁLISE DOS RESULTADOS}

Depois de rodar os dados no programa computacional GOLDVARB 2001, obtivemos resultados que atestam a hipótese de que a variante palatal do /s/ é a mais característica no falar dos informantes da Costa da Lagoa, com um percentual de $77 \%$ contra apenas $23 \%$ da variante alveolar, conforme vemos na Tabela 4 .

TABELA 4. Frequência global das variantes do /s/ em coda silábica

\begin{tabular}{c|c|c}
\hline Variante & Aplicação/Total & \% \\
\hline Palatal & $565 / 737$ & 77 \\
\hline Alveolar & $172 / 737$ & 23 \\
\hline
\end{tabular}

O programa estatístico selecionou, como variáveis mais influentes na realização da variante palatal do /s/, duas linguísticas - o contexto seguinte e o vozeamento; e duas 
sociais - a idade e a escolaridade. A primeira variável selecionada foi o contexto seguinte, a segunda a idade, a terceira a escolaridade seguida pelo vozeamento.

\subsection{Contexto seguinte}

Diferentemente dos resultados de Brescancini (1996), segundo a qual a variável contexto seguinte foi considerada menos significativa, nesta pesquisa, esta variável foi selecionada como a mais influente.

TABELA 5. Influência da variável 'contexto seguinte' para a palatalização do /s/ em posição de coda.

\begin{tabular}{c|c|c|c}
\hline Fator & Aplicação/Total & \% & Peso Relativo \\
\hline Dorsal & $141 / 156$ & 90 & 0,695 \\
\hline Coronal & $234 / 272$ & 86 & 0,625 \\
\hline Labial & $107 / 141$ & 75 & 0,450 \\
\hline Vogal & $22 / 87$ & 25 & 0,061 \\
\hline TOTAL & $504 / 656$ & 76 & \\
\hline
\end{tabular}

Conforme aparece na Tabela 5, como fatores mais favorecedores do fenômeno observado, surgem as consoantes dorsais com peso relativo elevado $(0,695)$. Esse resultado está de acordo com os resultados encontrados para essa variante por Brescancini (1996). Vemos ainda que a esse fator seguem as coronais com um peso relativo também alto $(0,625)$, deixando para trás as consoantes labiais. Os resultados deste estudo confirmaram assim a hipótese adotada no início do trabalho de Brescancini (1996) de que as consoantes coronais teriam um peso relativo alto, que não foi confirmada durante a análise dessa autora.

\subsection{Vozeamento dos segmentos seguintes}

A variável 'vozeamento dos segmentos seguintes' foi selecionada pelo programa como a quarta e última mais significativa em relação ao fenômeno estudado. A análise estatística corroborou a hipótese inicial - as consoantes surdas favorecem mais a palatalização da coronal anterior do que as sonoras, obtendo $87 \%$ e peso relativo 0,551 . Os outros dois fatores - zeroe as consoantes sonoras apresentam menor percentual e um baixo peso relativo e inclinando-se, dessa forma, ao desfavorecimento do fenômeno (ver Tabela 6).

TABELA 6. Influência da variável 'vozeamento do segmento seguinte' para a palatalização do $/ \mathrm{s} /$

\begin{tabular}{c|c|c|c}
\hline Fator & Aplicação/Total & \% & Peso Relativo \\
\hline Surdas & $414 / 474$ & 87 & 0,55 \\
\hline Zero & $57 / 78$ & 73 & 0,43 \\
\hline Sonoras & $70 / 99$ & 70 & 0,31 \\
\hline TOTAL & $541 / 615$ & 83 & \\
\hline
\end{tabular}

\subsection{Idade}

A variável idade foi selecionada como a segunda mais significativa. 
TABELA 7. Influência da variável 'idade' para a palatalização do /s/

\begin{tabular}{c|c|c|c}
\hline Fator & Aplicação/Total & \% & Peso Relativo \\
\hline+50 anos & $178 / 190$ & 93 & 0,86 \\
\hline $15-25$ anos & $125 / 162$ & 77 & 0,43 \\
\hline $26-50$ anos & $262 / 385$ & 68 & 0,30 \\
\hline TOTAL & $565 / 737$ & 76 & \\
\hline
\end{tabular}

Pelos resultados apresentados na Tabela 7, podemos confirmar que os indivíduos mais velhos palatalizam mais, seguidos pelos mais jovens (15 a 25 anos). Os informantes com idades entre 26 e 50 anos parecem palatalizar menos e desfavorecer o fenômeno estudado. Reparemos que o número de dados referentes à faixa etária entre 26 e 50 anos é mais do que o dobro apresentado pelas outras duas faixas Isso ocorre porque nessa faixa de 26 a 50 anos foram incluídos quatro informantes. Os resultados não corroboram as conclusões de Brescancini (1996), para a qual os mais jovens favoreceriam a palatalização.

\subsection{Escolaridade}

A variável escolaridade foi a terceira variável selecionada.

TABELA 8. Influência da variável 'escolaridade' para a palatalização do /s/

\begin{tabular}{c|c|c|c}
\hline Fator & Aplicação/Total & \% & Peso Relativo \\
\hline Primário & $349 / 450$ & 77 & 0,435 \\
\hline Superior & $216 / 287$ & 75 & 0,601 \\
\hline TOTAL & $565 / 737$ & 76 & \\
\hline
\end{tabular}

Pelo que observamos na Tabela 8, a distribuição do fenômeno em questão apresenta-se percentualmente bastante equilibrada, com a frequência $77 \%$ no nível primário e $75 \%$ no nível superior. Porém os resultados do peso relativo mostram uma diferença. Conforme vemos, os indivíduos com o nível superior apresentam peso relativo elevado $(0,601)$ se comparado ao peso relativo dos menos escolarizados que parece desfavorecer o fenômeno $(0,435)$. Temos de relembrar que não foi possível controlar o nível superior de escolaridade na faixa etária de acima de 50 anos.

Dos resultados da presente análise, poderíamos inferir que os informantes mais jovens da Costa da Lagoa apresentam a tendência ao uso da variante palatalizada. Para poder observar melhor a distribuição do fenômeno em estudo nas variáveis sociais, vamos ainda ver os resultados do cruzamento entre as variáveis escolaridade e idade.

TABELA 9. Cruzamento entre a variável 'escolaridade' e a variável 'idade'

\begin{tabular}{c|c|c|c|c}
\cline { 2 - 5 } & $15-25$ anos & $26-50$ anos & +50 anos & TOTAL \\
\hline primário & $51 / 74=69 \%$ & $120 / 186=65 \%$ & $178 / 190=94 \%$ & $349 / 450=78 \%$ \\
\hline superior & $74 / 88=84 \%$ & $142 / 199=71 \%$ & 0 & $216 / 287=75 \%$ \\
\hline TOTAL & $125 / 162=77 \%$ & $262 / 385=68 \%$ & $178 / 190=94 \%$ & $565 / 737=77 \%$ \\
\hline
\end{tabular}

A partir dos resultados apresentados na Tabela 9, podemos verificar que os mais escolarizados com idade inferior a 50 anos palatalizam mais do que os menos escolarizados nas mesmas faixas etárias. Se observarmos com atenção os dados, vemos 
que, especialmente os mais jovem com nível superior produzem o fenômeno com maior percentual (84\%), à exceção das informantes mais velhas com nível primário que apresentam um percentual de $94 \%$ de uso da variante palatizada. Uma hipótese interpretativa para esse resultado pode ser associada à recente valorização da identidade do "manezinho", ou seja, o orgulho de ser nativo da Ilha de Santa Catarina em relação aos "invasores de fora". Essa valorização da variante utilizada pelos 'manezinhos' já foi observada por Brescancini (1996).

É necessário ainda focalizar o fato de que não controlamos a variável sexo, a qual parece ser uma das mais significativas para a conservação do falar dos antepassados dos informantes. Infelizmente, dado o caráter breve do estudo, não foi possível controlá-la. O fator feminino mostrou uma grande importância no estudo de Brescanini (1996). Segundo as análises dessa autora, as mulheres com mais de 31 anos apresentam maior incidência de produção da variante palatal $(0,63)$, não muito distantes das mulheres de $15-30$ anos $(0,53)$. O fator masculino aponta para maior peso relativo nos jovens $(0,49)$ e na faixa de mais de 31 anos há um peso relativo baixo $(0,32)$ (BRESCANCINI, 1996).

\section{CONSIDERAÇÕES FINAIS}

Como variáveis estatisticamente mais relevantes no favorecimento da palatalização da fricativa alveolar em posição de coda silábica na fala dos informantes da Costa da Lagoa, foram selecionadas, por ordem de relevância estatística: contexto seguinte, idade, escolaridade e vozeamento.

A variável contexto seguinte mostrou que as consoantes dorsais e coronais favorecem a realização da variante palatal. A análise da variável vozeamento ratifica a hipótese inicial de que os segmentos surdos que seguem a variável dependente favorecem $o$ fenômeno de palatalização no falar dos informantes da Costa da Lagoa. A variável escolaridade mostrou-se mais relevante no cruzamento das duas variáveis sociais: os informantes que mais palatalizam são os mais escolarizados entre $15-25$ anos e entre 26 - 50 anos, e os menos escolarizados com idade acima de 50 anos. A variável idade revelou que os informantes na faixa etária de mais de 50 anos produzem mais o fenômeno, seguidos pelos informantes da faixa etária entre 15 - 25 anos. Os resultados corroboram grande parte dos achados de Brescancini (1996). Porém, ao contrário dos resultados dessa autora, no presente estudo, a variável contexto seguinte se mostrou bastante significativa.

Este estudo traz novas análises sociolinguísticas sobre o falar de uma das regiões mais tradicionais e mais preservadas da Ilha de Santa Catarina. Contribui para o nosso conhecimento sobre uma das variantes do português falado no Brasil e pode servir de referência para quem queira comparar seus resultados com as conclusões sobre as realizações de pronúncia do /s/ em posição de coda silábica em outras variantes no estado ou no país.

\section{BIBLIOGRAFIA}

BRESCANCINI, Cláudia Regina. A Palatalização a fricativa alveolar não-morfémica em posição de coda no português falado em três regiões de influência açoriana do 
município de Florianópolis - uma abordagem não-linear. Dissertação de Mestrado. UFSC, 1996.

GIMENO, Silvia Ines Dufech. O destino viaja de barco: um estudo histórico, político e social da Costa da Lagoa e de seu processo de modernização-1930-1990. Dissertação de Mestrado. UFSC, 1992.

KUHNEN. A Bacia da Lagoa da Conceição, Santa Catarina. Projeto marca d'água, relatórios preliminares. Florianópolis, 2001.

LABOV, William. Padrões sociolinguísticos. Trad. Marcos Bagno, Maria Marta Pereira Scherre e Caroline R. Cardoso. Parábola Editorial: São Paulo, 2008.

SAUSSURE, Ferdinand. Curso de Linguística Geral. Trad. Antônio Chelini, José Paulo Paes e Izidoro Blikstein. Cultrix: São Paulo, 1977.

TEYSSIER, Paul. História da Língua Portuguesa. Trad. Celso Cunha. Sá de Costa: Lisboa, 1984.

WEINREICH, Uriel. LABOV, William. HERZOG, Marvin I. Mudança Linguística. Trad. Marcos Bagno. Parábola Editorial: São Paulo, 2006.

Censo Demográfico IBGE 2000 (Estimativa 2008) atualizado em dezembro de 2008 Disponível em: http://www.pmf.sc.gov.br/saude/unidades_saude/populacao/ulst_2008.php Acesso em: 15. 7. 2009. 